\title{
P16
}

\section{Differential Fracturing Pattern in Clay/limestone Alternations and Fluid Circulations in the Maltese Islands}

\author{
Y. Missenard* (Paris-Sud 11 University), M. Rocher (IRSN), P. Vergely \\ (Paris-Sud 11 University), L. Casteleyn (University of Cergy-Pontoise), P. \\ Robion (University of Cergy-Pontoise), M.E. Cushing (IRSN), A. Bertrand \\ (Paris-Sud 11 University) \& A. Benedicto (Paris-Sud 11 University)
}

\section{SUMMARY}

Draining faults propagating from carbonates to clay layers could significantly impact the safety of nuclear waste storages, as investigated in the Bure Underground Research Laboratory (URL, France). In this study, we show that the draining properties of such faults seem to depend mainly of the fault throw magnitude. The results obtained on the Maltese Islands indicate that large faults (throw $>50 \mathrm{~m}$ ) as well as small faults (throw $<5 \mathrm{~m}$ ) does not lead to fluid circulation. On the opposite, intermediate faults propagates in the clay formation and lead to significant fracturation and fluid flows, including associated mineralisations. 
IRSN has reviewed ANDRA's 2005 clay dossier on the feasibility of deep geological disposal of high level, long-lived radioactive waste in the Callovo-Oxfordian clay formation (COX) located in the Meuse/Haute-Marne (MHM) area, Eastern Paris Basin, and investigated by ANDRA using the Bure Underground Research Laboratory (URL). An important task was to deal with the influence of tectonic structures, which is a key question of the safety evaluation as they may have potential for locally leading to a channelling of flows through the sedimentary beds and thus for affecting transfer times, dilution factors and outlet positions.

Using available data from ANDRA's geological survey, IRSN suspected the existence of faults belonging to the same fault family, but with a different expression within the Mesozoic sedimentary pile: near the Bure URL, faults suspected under the Lower Bathonian (using a 3D seismic survey) do not seem to have propagated through the COX (according to oblique boreholes), whereas a few kilometers to the SW, structural and hydrogeological data (from boreholes) allow to postulate that neighbouring faults hydraulically impact the entire sedimentary pile, including the COX. Therefore, given these possible differences in fault propagation, the fracturing pattern in the COX can not be straightforwardly extrapolated to the whole MHM area.

The propagation of fractures from limestones to clays is related to the so-called "differential fracturing phenomenon", which means that ductile layers (clays) show a less intense and concentrate fracturing than do breaking layers (such as limestones). This is commonly observed at a decimeter scale and has been studied for joints, but it is still insufficiently understood for faulting at the scale of tens to hundreds meter thick formations. This poorly understood phenomenon is being addressed by IRSN on the basis of field observations at analog sites at various scales, so as to elaborate a model of differential fracturing in clay/limestone alternations. First fracturing observations were carried out in two analog sites, Tournemire (Aveyron, France) and the Maltese Islands.

The present paper intends to describe the results obtained on the Maltese Islands and summarized below.

In the Maltese Islands, along the seashore, the $70 \mathrm{~m}$ thick Blue Clays outcrop between two tens of meters thick limestone formations of Oligo-Miocene age affected by slight extensional tectonics. The underlying limestone layers show numerous joints and faults. Some fractures have conducted fluids from limestones to clays; others seem to have been generated by fluid overpressure. The relationship between these fractures and the fluid circulations is clearly expressed by oxidation phenomenon (Fig. 1). Field evidences indicate that these circulations occurred after the deposition of the whole sedimentary pile, but before the last tectonic stages (probably Plio-Quaternary in age).

As most of the joints do not seem to propagate in the Blue Clay formation, we focus our study on the draining or sealing capacity of the normal faults from the lower Limestones to the Blue clay formation. Three families of faults are identified regarding their throw and draining properties: large faults (throw of $50 \mathrm{~m}$ or more), intermediate faults (throw comprised between 5 to $50 \mathrm{~m}$ ) and small faults (throw lower than $5 \mathrm{~m}$ ).

The large faults show typical sealing structures. The whole sedimentary pile, from the Lower to the Upper Limestones, is affected by the deformation. In the limestones, the deformation zone is relatively thin (i.e. no more than a few meters) and includes cataclasites and Riedel shears. The Blue Clays are smeared into the fault zone and strongly deformed along the fault plane. However, no evidence of fluid circulation has been found, and it is likely that these large faults behave as a barrier preventing fluids to circulate vertically as well as laterally in the sedimentary sequence.

The small faults (throw lower than $5 \mathrm{~m}$ ) are well expressed in the lower limestones. They are locally bordered by oxidation bands when penetrating into the overlying clays, indicating that they may drain fluids into this series. Nevertheless, the oxidation evidences are only visible on a restricted area, that is a few decimeters above the fault, and these faults seem to stop in the clays, where the deformation is though to be distributed.

On the contrary, the intermediate faults have a clear expression in the clay sequence. In the Limestones, the fault zone is only a few centimeters thin and deformation is localized and 


\section{Fault and Top Seals \\ Montpellier 2009}

well defined in a limited zone. When penetrating into the Blue Clays sequence, the deformation zone looks wider and the fault plane cannot be followed. The deformation in the clays is expressed by a large set of plurimetric joints whose mean direction is parallel to the fault one. These joints are almost systematically filled with gypsum veins up to $5 \mathrm{~cm}$ thick (Fig. 2). They are also underlined by a $10 \mathrm{~cm}$ large amber oxidation shade (Fig. 2). These observations indicate that although the fault throw is moderate, significant fluid circulation can be triggered through opened fractures in the Blue Clays formation.

This study thus shows that brittle deformation and associated fluid circulations can occurred in an even poorly consolidated clay layer, as it is the case on the Maltese Islands. Further investigations are in progress to assess the impact of the fluids on the mechanical and mineralogical properties of the Blue Clays and limestone formations.

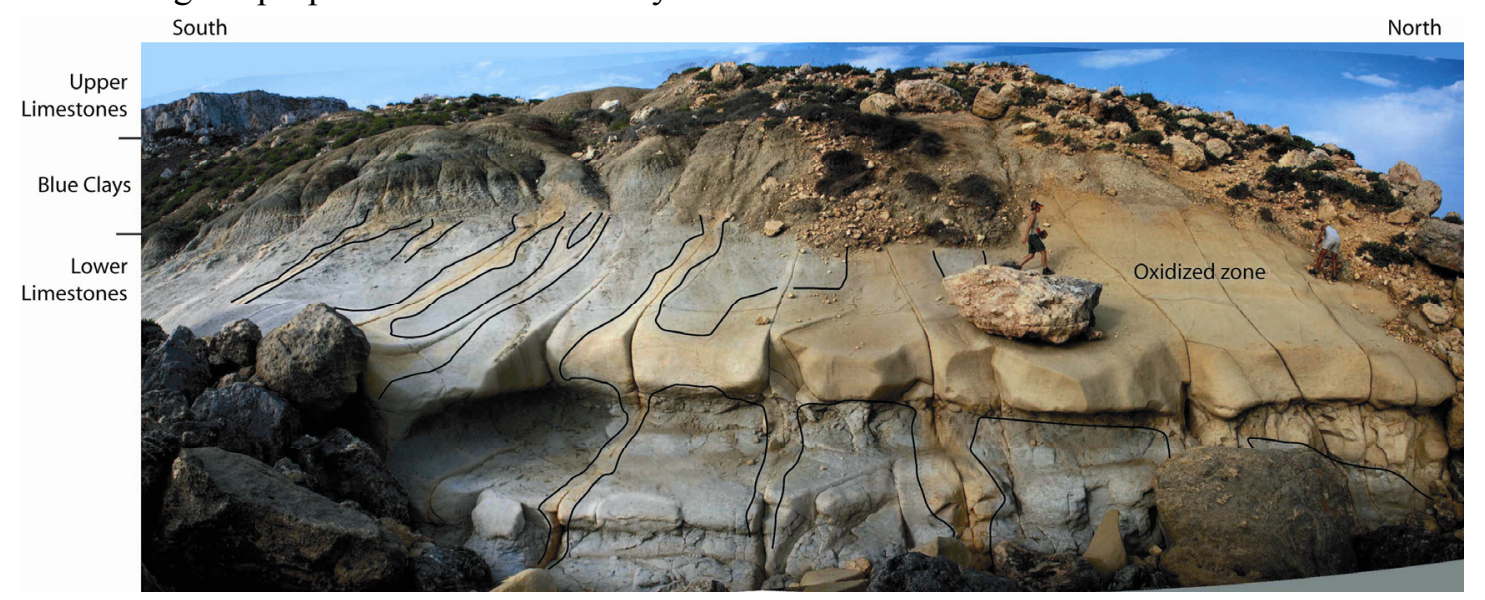

Figure 1 Picture of the El Imgiebah outcrop, North coast of Malta. This picture shows the Lower Limestones below the Blue Clay formation. In the northern part of the outcrop, the limestones present an ochre colour interpreted as an oxidation phenomenon in response to fluid circulation. The fluid seems to have propagated southward and upward or downward along the numerous joints visible on the picture.

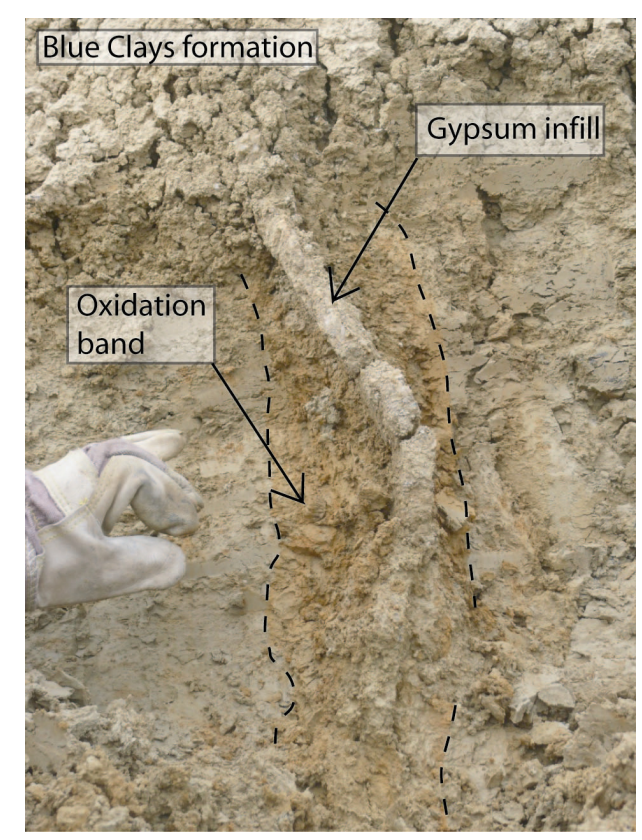

Figure 2 Example of a joint in the Blue Clay formation. This joint is located above an intermediate fault well expressed in the Lower Limestones. It is underlined by oxidation bands and filled with a thick gypsum vein. 